Book Announcement: FUNGICIDE AND NEMATICIDE TESTS, RESULTS OF 197.2.

This report is issteed annually by The American Phytopathological Society Committee on New Fungicicle and Nematicide Data. Volume 28 contains the results of 348 experiments from 34 states of the United States, Australia. Canada. Chile, Ecuador, Greece, India, Israel, Libya, Mexico, New Zealand and the United Kingdom. It also includes an index of all fungicicles and nematicides reported, a description of the materials available for testing in 1973.

This book is available for $\$ 3.00$ per copy when payment accompanies the order, or $\$ 2.50$ per copy for 100 or more copies mailed to one address. Reports for 1970 and 1971 are available at $\$ 3.00$ per copy. Copies of the reports for 1960 through 1965 plus a few older copies are available at $\$ 1.00$ per copy plus the usual charge of $25 \phi$ per copy if billing is required. Make remittances to the American Phytopathological Society and send orders to K. D. Hickey, Virginia Polytechnic Institute and State University, Fruit Researcl Laboratory, 2500 Valley Avenue. Winchester, Virginia 22601.

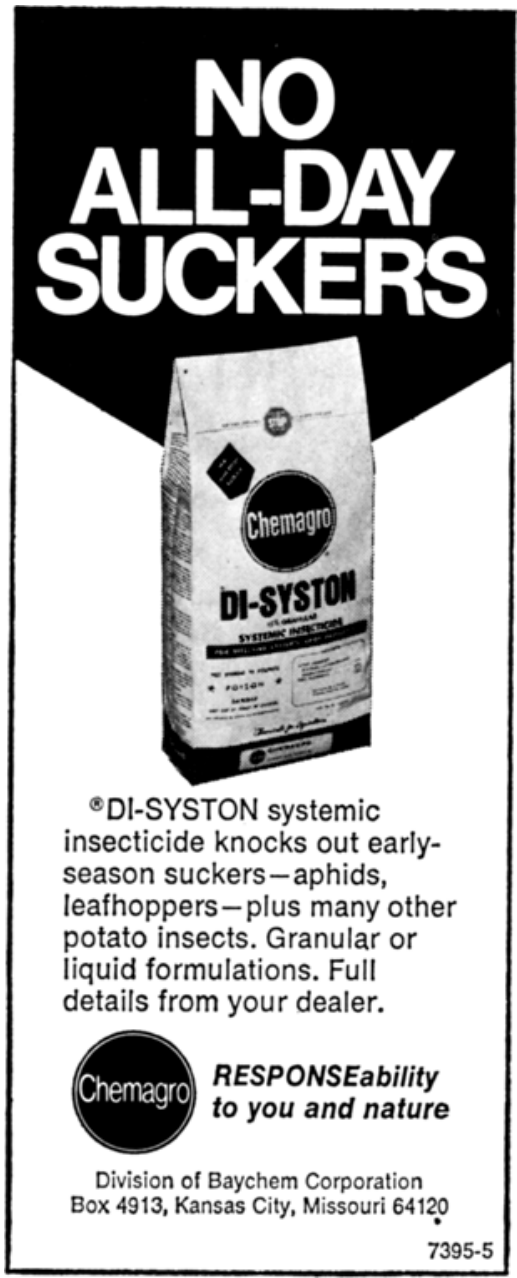

\title{
ANNOUNCEMENT OF NEW PUBLICATION - SCIENTIA HORTICULTURAE
}

The International Society For Horticultural Science has announced the publication of a new journal. Scinntia Horticulturae.

The periodical is a general horticultural journal dealing with crops (vegetables, fruits, nuslirooms. bullss and ornamentals) under moderate, stubtropical and tropical conclitions.

The journal is published in one volume yearly. comprising four isstues and the subscription price is Dfl. 72.00 per volume. plus Df. 8.00 for postage and handling. Free sample copies are available from Elsevier Publishing Company, Journal Division, P.O. Box 211, Amsterdam, The Netherlands. 